ISSN electrónico: $1885-5210$

DOI: https://doi.org/10.14201/rmc20201612936

\title{
DESCRIPCIÓN Y ANÁLISIS DEL CONTENIDO BIOMÉDICO EN LAS PELÍCULAS DE LA SAGA ALIEN
}

\section{Description and analysis of biomedical content in movies from the Alien saga}

\author{
José Miguel BISCAIA FERNÁNDEZ; Rosa Belén MOHEDANO DEL POZO² \\ ${ }^{1}$ Departamento de Ciencias Biomédicas Básicas. ${ }^{2}$ Departamento de Farmacia, Biotecnología y Nutrición. Facultad de Ciencias \\ Biomédicas. Universidad Europea de Madrid. Villaviciosa de Odón (España).
}

e-mail: josemiguel.biscaia@universidadeuropea.es

Fecha de recepción: 11 de julio de 2019

Fecha de aceptación: 16 de septiembre de 2019

Fecha de publicación: 15 de marzo de 2020

\section{Resumen}

El cine de Ciencia-Ficción se ha convertido en un muestrario de los últimos avances tecnológicos y de la vanguardia y especulación científica. Puede, por ello, ser utilizado como herramienta de divulgación y como recurso formativo. Sin embargo, si se quiere diferenciar lo real y plausible de lo fantástico e imposible, se hace necesario tener una mirada rigurosa del material tecnocientífico que nos presenta. En el presente estudio se describe y analiza el contenido biomédico de las películas de la saga Alien. De las diferentes áreas de conocimiento catalogadas por el Ministerio de Educación, Cultura y Deporte de España, encontramos que al menos 37 de ellas, relacionadas con temas biosanitarios, se trataban con diferente profundidad en la saga, destacando especialmente la Microbiología y Parasitología Clínica o la Fisiología y Anatomía Humanas. Aun admitiendo las licencias artísticas del género fantástico al que pertece la saga, creemos que el contenido y tratamiento biomédico de estas obras podría ser utilizado como recurso docente para estudiantes de diferentes grados biosanitarios como Medicina, Enfermería, Farmacia u Odontología.

Palabras clave: ciencia-ficción; microbiología; parasitología; anatomía; fisiología; docencia.

\section{Summary}

The Science-Fiction movies have become a showcase of the latest technological advances and vanguard and scientific speculation. It can, therefore, be used as a divulgation tool and as a training resource. However, if you want to differentiate the real and plausible from the fantastic and impossible, it is necessary to have a rigorous look of the techno-scientific material that presents us. In the present study, the biomedical content of the films of the Alien saga is described and analyzed. Of the different areas of knowledge cataloged by the Ministry of Education, Culture and Sports of Spain, we found that at least 37 of them, related to biosanitary issues, were treated 


\title{
DESCRIPCIÓN Y ANÁLISIS DEL CONTENIDO BIOMÉDICO EN LAS PELÍCULAS DE LA SAGA ALIEN \\ JOSÉ MIGUEL BISCAIA FERNÁNDEZ; ROSA BELÉN MOHEDANO DEL POZO
}

\begin{abstract}
with different depth in the saga, highlighting especially the Microbiology and Clinical Parasitology or the Human Physiology and Anatomy. Even admitting the artistic licenses of the fantastic genre to which the saga belongs, we believe that the content and biomedical treatment of these works could be used as a teaching resource for students of different biosanitary degrees such as Medicine, Nursing, Pharmacy or Dentistry.

Key words: science-fiction; microbiology; parasitology; anatomy; physiology; teaching.
\end{abstract}

\section{Introducción}

La ciencia y la tecnología han tenido un desarrollo sin precedentes en los últimos cien años. Gracias a sus logros, la sociedad moderna ha alcanzado un progreso exponencial. Esta indiscutible influencia cristalizó en los años 60 con el nacimiento de una nueva disciplina académica, denominada Ciencia, Tecnología y Sociedad. Entre las características de su campo de acción, el sociólogo inglés John Ziman destaca la total inmersión de la tecnociencia en el debate público y en la cultura de masas $^{1}$, siendo el cine una de las más influyentes herramientas para vehicular con sus tramas la vanguardia científica y tecnológica. Así, teniendo en cuenta la potencia comunicadora del séptimo arte, se antoja necesario que la sociedad actual tenga la suficiente cultura científica como para poder diferenciar la verdad de la falsedad, lo plausible de lo imposible.

El cine, además, puede ser útil como herramienta de aprendizaje. En el área biomédica, por ejemplo, son muchos los casos de su alcance divulgador: el personaje Colosus, de la saga $X-M e n$, ha sido utilizado para explicar algunos de los rasgos más destacados de la piel²; el superheroroe Capitán América, de la factoría Marvel, ha servido de excusa para tratar diferentes aspectos de la fisiología humana ${ }^{3}$ (ambos basados en comic); incluso, las fantásticas capacidades de los vampiros se han utilizado para la enseñanza en el área de la inmunología ${ }^{4}$. Por otro lado, hay estudios que demuestran que visionar y discutir sobre películas de temática biosanitaria supone un estímulo en el aprendizaje clínico ${ }^{5}$ y una mejoría en las habilidades humanísticas (actitud y trato hacia los pacientes) de los estudiantes de Medicina ${ }^{6}$ y Enfermería ${ }^{7}$.

Las películas de la saga Alien son un excelente ejemplo de obras de Ciencia-Ficción futurista y espacial, que están cargadas además de abundante contenido biomédico susceptible de ser utilizado como material docente. Aunque el orden de estreno de las películas que forman esta saga ( $\sin$ contar con los dos crossovers del personaje Predator) es el que se indica en la tabla 1 , el orden cronológico de la historia varía de forma considerable: Prometheus (2012) de Ridley Scott, muestra el origen de la criatura Alien, también el de toda la humanidad; Alien: Covenant (2017) de Ridley Scott, sería una secuela de la obra anterior; la primera que se estrenó en la gran pantalla, Alien, el octavo pasajero (1979), de Ridley Scott, con Sigourney Weaver como protagonista, vendría después; las tres siguientes son las secuelas de la superviviente Ripley: Alien: El regreso (1986) de James Cameron, Alien $^{3}$ (1992) de David Fincher y Alien: resurrección / Alien Resurrection (1997) de Jean-Pierre Jeunet.

\section{Objetivos}

Con este estudio se pretenden alcanzar tres grandes objetivos:

- Identificar y describir temáticas biosanitarias en las películas de la saga Alien, asignando a dicha área de conocimiento la nominación seguida por el Ministerio de Educación, Cultura y Deporte de España (MECD).

- Analizar el rigor científico y la plausibilidad de lo narrado desde el punto de vista biomédico.

- Ofrecer una discusión biosanitaria susceptible de ser utilizada como recurso docente en grados biomédicos.

\section{Obras analizadas y metodología seguida}

La elección de las películas de la saga Alien se debió fundamentalmente a su pertenencia al género de la Ciencia-Ficción, a la gran pluridisciplinaridad de los temas biomédicos tratados y a su icónica influencia cultural.

De los 8 largometrajes que versan sobre el xenomorfo Alien, centramos el estudio en 6 de ellos, decartando los 2 en los que se realizó un crossover con el personaje de ficción Depredador: Alien vs Predator (2004) y Alien vs Predator 2, (2007). Las películas fueron visionadas a partir del repositorio de la Biblioteca CRAI Dulce Chacón de la Universidad Europea de Madrid. En la tabla 1 se recogen los principales datos técnicos y artísticos de las obras estudiadas. 


\section{DESCRIPCIÓN Y ANÁLISIS DEL CONTENIDO BIOMÉDICO EN LAS PELÍCULAS DE LA SAGA ALIEN JOSÉ MIGUEL BISCAIA FERNÁNDEZ; ROSA BELÉN MOHEDANO DEL POZO}

Durante el visionado de las películas, se identificaron aquellas escenas en las que aparecían temáticas que se podían vincular con las diferentes áreas de conocimiento biosanitario que recoge la Agencia Nacional de Evaluación de la Calidad y la Acreditación, ANECA (BOE, Real Decreto 415/2015 de 29 de mayo. Ministerio de Educación, Cultura y Deporte, MECD) ${ }^{8}$. Dada la amplitud de materias, únicamente se describieron y analizaron después aquellas que tenían mayor relevancia cuantitativa y cualitativa.

\section{Resultados y discusión}

\section{Identificación de elementos biomédicos en las películas de la saga Alien}

Atendiendo a los criterios del MECD, se encontraron al menos 37 áreas de conocimiento biosanitario tratadas en las obras que se estudiaron. Dichas áreas (y la nomenclatura para designarlas, tal y como recoge la ANECA) fueron:

Tabla 1. Ficha técnica de las películas analizadas.

\begin{tabular}{|c|c|c|c|c|c|c|}
\hline Carátula & ${ }^{4}$ & 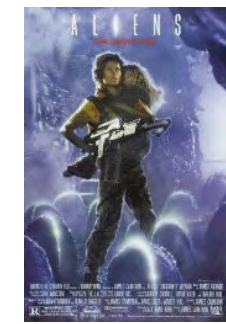 & 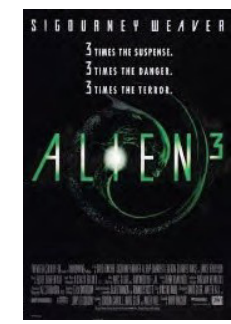 & (19) & a. & 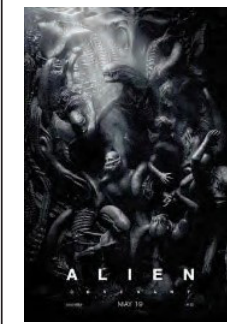 \\
\hline Título & $\begin{array}{l}\text { Alien, el octavo } \\
\text { pasajero }\end{array}$ & Aliens: El regreso & Alien3 & Alien: Resurrección & Prometheus & Alien: Covenant \\
\hline Año & 1979 & 1986 & 1992 & 1997 & 2012 & 2017 \\
\hline Director & Ridley Scott & James Cameron & David Fincher & Jean-Pierre Jeunet & Ridley Scott & Ridley Scott \\
\hline $\begin{array}{l}\text { Duración } \\
\text { (minutos) }\end{array}$ & 116 & 150 & 115 & 108 & 123 & 123 \\
\hline Productora & $\begin{array}{l}\text { 20th Century Fox } \\
\text { / Brandywine } \\
\text { Productions }\end{array}$ & $\begin{array}{l}\text { 20th Century Fox } \\
\text { / Brandywine } \\
\text { Productions }\end{array}$ & $\begin{array}{l}\text { 20th Century Fox } \\
\text { / Brandywine } \\
\text { Productions }\end{array}$ & $\begin{array}{l}\text { 20th Century Fox } \\
\text { / Brandywine } \\
\text { Productions }\end{array}$ & $\begin{array}{l}\text { 20th Century Fox / } \\
\text { Scott Free Productions } \\
\text { / Dune Entertainment } \\
\text { / Brandywine } \\
\text { Productions }\end{array}$ & $\begin{array}{l}\text { 20th Century Fox } \\
\text { / Scott Free } \\
\text { Productions } \\
\text { / Brandywine } \\
\text { Productions }\end{array}$ \\
\hline $\begin{array}{l}\text { Enlace } \\
\text { (imdb) }\end{array}$ & $\begin{array}{l}\text { https://www. } \\
\text { imdb.com/title/ } \\
\text { tt0078748/?ref_=fn_ } \\
\text { al_tt_1 }\end{array}$ & $\begin{array}{l}\text { https://www. } \\
\text { imdb.com/title/ } \\
\text { tt0090605/?ref_=fn_ } \\
\text { al_tt_1 }\end{array}$ & $\begin{array}{l}\text { https://www. } \\
\text { imdb.com/title/ } \\
\text { tt0103644/?ref_=fn_ } \\
\text { al_tt_4 }\end{array}$ & $\begin{array}{l}\text { https://www. } \\
\text { imdb.com/title/ } \\
\text { tt0118583/?ref_=fn_ } \\
\text { al_tt_1 }\end{array}$ & $\begin{array}{l}\text { https://www. } \\
\text { imdb.com/title/ } \\
\text { tt1446714/?ref_=fn_ } \\
\text { al_tt_1 }\end{array}$ & $\begin{array}{l}\text { https://www. } \\
\text { imdb.com/title/ } \\
\text { tt2316204/?ref_=nv_ } \\
\text { sr_1?ref_=nv_sr_1 }\end{array}$ \\
\hline
\end{tabular}

A. Ciencias:

- A.4. Ciencias de la Naturaleza: 028. Antropología Física.

- A.5. Biología Celular y Molecular: 050. Biología Celular. 060. Bioquímica y Biología Molecular. 420. Genética.

B. Ciencias de la Salud:

- B.6 Ciencias Biomédicas: 020. Anatomía Patológica. 025. Anatomía y Anatomía Patológica Comparadas.
027. Anatomía y Embriología Humana. 410. Fisiología. 443. Histología. 566. Inmunología. 630. Microbiología. 660. Parasitología. 807. Toxicología.

- B.7. Medicina Clínica y Especialidades Clínicas: 090. Cirugía. 183. Dermatología. 275. Estomatología. 610. Medicina. 613. Medicina Legal y Forense. 645. Obstetricia y Ginecología. 646. Oftalmología. 653. Otorrinolaringología. 670. Pediatría. 745. Psiquiatría.
Rev. Med. Cine. 2020; 16(1), 29-36
J. Med. Mov., 2020; 16 (1), 29-36 


\section{DESCRIPCIÓN Y ANÁLISIS DEL CONTENIDO BIOMÉDICO EN LAS PELÍCULAS DE LA SAGA ALIEN JOSÉ MIGUEL BISCAIA FERNÁNDEZ; ROSA BELÉN MOHEDANO DEL POZO}

770. Radiología y Medicina Física. 817. Urología. 830. Traumatología y Ortopedia.

- B.8. Especialidades Sanitarias: 255. Enfermería. 413. Fisioterapia. 310. Farmacia y Tecnología Farmacéutica. 315. Farmacología. 640. Nutrición y Bromatología. 615. Medicina Preventiva y Salud Pública.

D. Ciencias Sociales y Jurídicas.

- D.17. Ciencias del Comportamiento: 620. Metodología de las Ciencias del Comportamiento. 680. Personalidad, Evaluación y Tratamiento Psicológico. 725. Psicobiología. 730. Psicología Básica. 735. Psicología Evolutiva y de la Educación.

De las 37 áreas biosanitarias registradas, 5 de ellas tenían a nuestro juicio una relevancia destacada: Microbiología (630), Parasitología (660), Anatomía Comparada y Humana (025 y 027) y Fisiología (410). Las razones de su importancia fueron: la aparición transversal en todas las películas que se analizaron, la preponderancia en el currículo biomédico de grados biosanitarios y su alto valor formativo, docente y divulgador. Por tanto, aunque estas 5 áreas son las que se discuten a continuación, el siguiente análisis no agota las posibilidades «biodocentes» de la saga.

\section{Descripción y análisis de elementos biomédicos en las películas de la saga Alien}

El xenomorfo Alien (inspirado en las obras pictóricas Necronom IV y $V$, del artista suizo H.R. Giger) presenta una morfología y un ciclo biológico inspirado en ciertos animales y parásitos / parasitoides del reino animal, algunos de los cuales son de interés clínico. Para empezar, existen al menos dos morfologías (o castas) diferenciadas para los adultos: la reina, por un lado, de mayor tamaño y ovípara (con la excepción de Alien: Resurrección (1997), donde se presenta a una criatura vivípara, fruto de experimentos genéticos), es la encargada de la reproducción de la colonia mediante la puesta de huevos; por otro lado, encontramos individuos adultos a los que por sus funciones cabría denominar como «obreros» y/o «soldados» (Foto 1). Es, por tanto, una especie con una marcada jerarquía anatomo-funcional y una muy compleja organización social, todo ello en clara alusión a los artrópodos del orden Hymenoptera, como las hormigas o las abejas (de hecho, en Aliens: El regreso (1986) se muestra su forma de vida en una colonia).

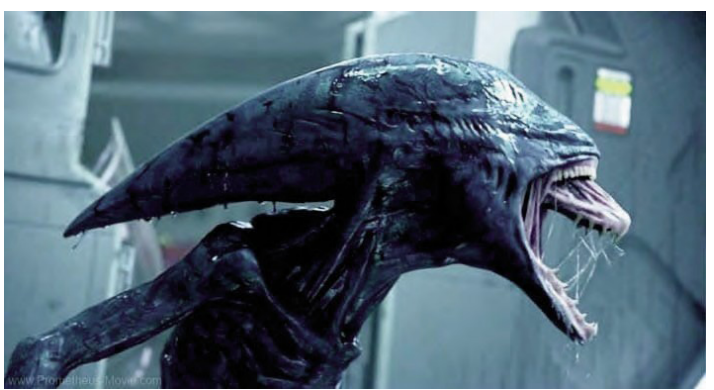

Foto 1. Morfología adulta de la criatura Alien.

La especie podría tener una reproducción sexual (en Alien: El regreso (1986) se muestra la ovoposición de la hembra), mostrando similitudes con ciertos parásitos de interés médico que también realizan este tipo de reproducción, como Diphyllobothrium latum (conocida coloquialmente como «la tenia del pescado», en alusión al alimento que actúa de vehículo en la transmisión fecal-oral en la patología humana). Puede sorprender, no obstante, que en ninguna escena aparezcan machos reproductores ni acto alguno de copulación o fertilización en el ciclo vital de Alien. Es posible plantear varias justificaciones a tal hecho. Una de ellas nos lleva a pensar que pudiera tratarse de un ser hermafrodita, tal es el caso de algunos gusanos del tipo cestodo como la ya mencionada Diphyllobothrium latum, pero también como Taenia saginata, Taenia solium o los géneros Echinoccocus, Hymenolepis y Dipylidium. Como curiosidad, es interesante añadir que estos parásitos enunciados, en realidad poseen un hermafroditismo llevado al extremo, pues cada uno de los segmentos (o proglótides) que constituyen su morfología es hermafrodita de forma independiente con respecto a las demás ${ }^{9}$. Dicho lo cual, nada hace sospechar que Alien posea dicho hiper-hermafroditismo por proglótide.

Otra de las explicaciones, en el caso de ausencia de machos copuladores, tendría que ver con una probable existencia de hembras partenogenéticas. No en vano, este tipo de reproducción es bien conocido en el contexto de ciertos parásitos como Strongiloides stercoralis, nematodo intestinal en cuyo ciclo sexual dentro del ser humano no se ha podido demostrar la presencia de machos ${ }^{9}$.

Volviendo a la descripción del modo de vida de Alien, se observa que, de los huevos, emergen unas criaturas (podrían ser designadas como "atrapacaras» por la función que se describirá más adelante) de cuyo cuerpo salen varias extremidades (su morfología artrópoda es 
similar a la de los arácnidos o crustáceos), lo que parece ser una probóscide y una cola prensil (Foto 2). Esta forma intermedia podría considerarse como una especie de vehículo, ya que tras acoplarse a la región craneofacial del hospedador introduce (presumiblemente) una especie de larva (que sería la supuesta forma infectante) en la orofaringe, lo que podría equivaler a una transmisión infecciosa fecal-oral, según la Microbiología Clínica. En la naturaleza existen parásitos que también utilizan larvas como forma infectante, tal es el caso de ciertos nematodos intestinales, como Ascaris lumbricoides. Este agente parasitario emplea la larva en estadio $L 2$ y es ésta la que tiene capacidad para ingresar en el organismo humano que va a actuar de huésped, a través de la ingesta de alimentos o bebidas contaminados. Otros nematodos intestinales, como las uncinarias (entre las que destacan Necator americanus y Ancylostoma duodenale), también utilizan su forma larvaria para infectar al ser humano. Sin embargo, en estos últimos ejemplos el estadio larvario infectante es el L3 (denominado también larva filariforme) y su transmisión no es oral-fecal, sino por medio de la piel, incluso aunque el tejido cutáneo humano esté intacto y no hubiera previamente ninguna solución de continuidad ${ }^{9}$.

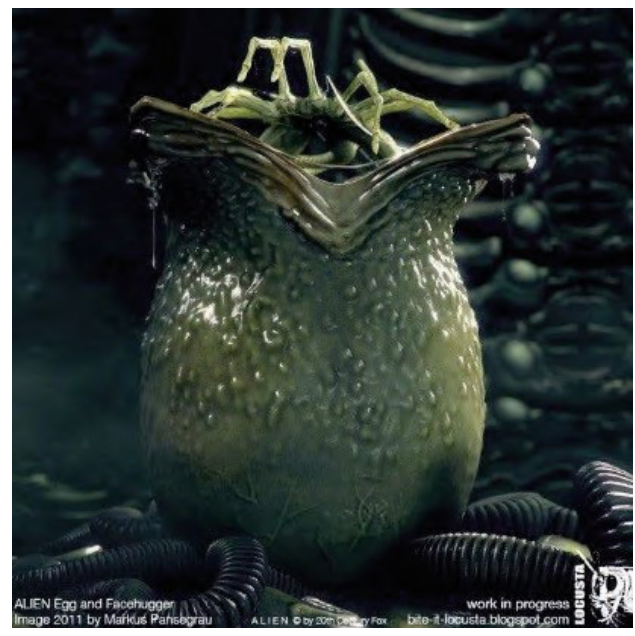

Foto 2. Eclosión de un huevo de Alien y emergencia del vehículo «atrapacaras».

Pasado un periodo de incubación, que oscila entre unas pocas horas, a juzgar por Alien, el octavo pasajero (1979), y hasta 7 días, como se muestra en Alien $^{3}$ (1992), surge del hospedaror un individuo que en la mayoría de los casos no presenta aun la morfología adulta (Foto 3), por lo que podría considerarse una especie de ninfa (como en los insectos que realizan metamorfosis sencilla) o pupa móvil (como en algunos insectos del orden Diptera que realizan holometabolía). Sin embargo, si tomamos los datos que ofrece la Parasitología Médica, lo más habitual es que la forma parasitaria que emerge del cuerpo del hospedador humano sea una forma adulta. En cualquier caso, abandonado el cuerpo del huésped, la criatura parece realizar un cambio corporal importante (podría considerarse, incluso, una metamorfosis), puesto que tanto en la primera obra de la saga como en la tercera se muestra una especie de muda de piel o cutícula. Lo que resulta del todo incoherente desde el punto de vista metabólico es el apresurado crecimiento de la criatura: en apenas unas horas adquiere el tamaño y morfología adulta definitiva, y, en el caso de Alien, el octavo pasajero (1979) sin, incluso y misteriosamente, nutrirse de alimento alguno.

Durante la fase infectiva del ciclo vital de la criatura Alien, la larva debe acceder, desarrollarse y finalmente abandonar el cuerpo del hospedador. De este periodo facultativo de su ciclo vital puede obtenerse, pues, una muy interesante información anatomo-funcional que se discute a continuación.

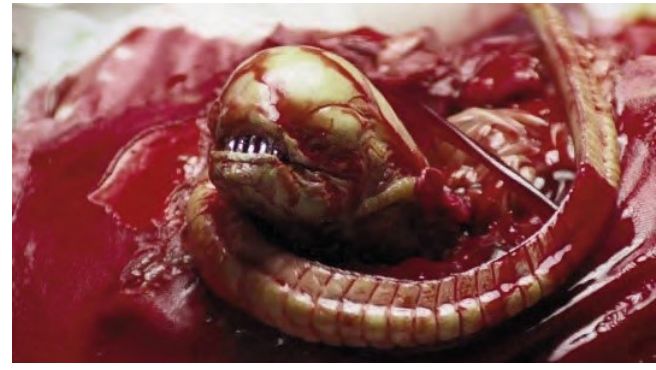

Foto 3. Forma juvenil de la criatura Alien.

Como se dijo más arriba, el «atrapacaras» se acopla a la región craneo-facial, rodeando el cuello del hospedador con su cola prensil (Foto 4). Durante este proceso, sus víctimas quedan paralizadas, por lo que no sería descabellado especular que la criatura utiliza algún tipo de anestésico o sedante, un poco al modo de ciertos animales hemafófagos, como el heteróptero triatomino Rhodnius prolixus (que es el vector de Trypanosoma cruzi, causante de la enfermedad de Chagas) ${ }^{10}$. La pérdida de consciencia también podría producirse por la reducción 


\section{DESCRIPCIÓN Y ANÁLISIS DEL CONTENIDO BIOMÉDICO EN LAS PELÍCULAS DE LA SAGA ALIEN JOSÉ MIGUEL BISCAIA FERNÁNDEZ; ROSA BELÉN MOHEDANO DEL POZO}

momentanea de la entrada de oxígeno como consecuencia de la compresión sobre el cuello. En cualquier caso, la inconsciencia del huesped facilitaría la deposición de la larva, evitando daños tisulares y anulando el reflejo de la nausea.

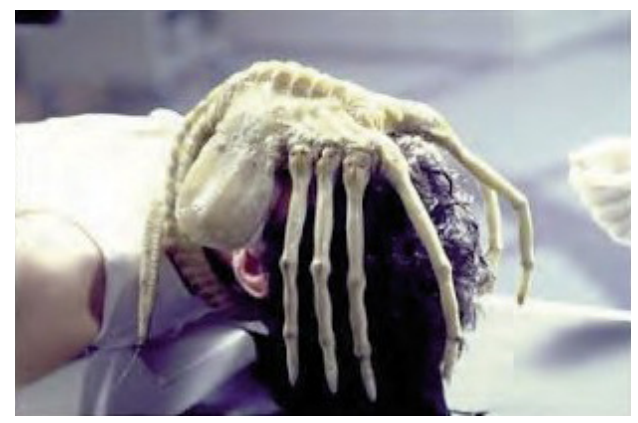

Foto 4. "Atrapacaras» acoplado a la región craneofacial del huésped humano.

El «atrapacaras» introduce la larva en la región orofaringea del huésped a través de una especie de probóscide ovopositora. Una vez aquí, lo más probable es que la larva viaje a través del esófago en dirección al estómago, donde completaría su desarrollo, dado el gran volumen de este órgano (puede distenderse hasta los 4 litros) y su naturaleza ácida (el ácido clorhídrido del estómago, fabricado por las células parietales de las glándulas fúndicas, crea un ambiente de $\mathrm{pH}$ reducido, ideal para una criatura cuya sangre es -sorprendentemente- muy ácida). En principio, se descarta el aparato respiratorio (laringe-tráquea-bronquios) como vía de acceso, dadas sus menores dimensiones y por la asfixia que produciría al hospedador, si es que el tamaño de la larva fuera considerable. Además, hay dos escenas que prueban la idea del aparato digestivo como residencia temporal de la larva: en Prometheus (2012), una prueba de imagen situa al xenomorfo en la cavidad abdominal (parece, no obstante, que en una posición un tanto inferior con respecto al estómago, puede que ocupando parte del intestino). Además, Alien: Resurrección (1997) utiliza una ingeniosa escena que imita el recorrido visual de una laparoscopia a través del esófago y el estómago para mostrar la ocupación de la larva. También, si su tamaño fuese inicialmente muy reducido, podría absorberse a través de la mucosa intestinal, diseminarse a sangre y llegar a tejidos extraintestinales. Además, aceptando esta última premisa sobre sus pequeñas dimensiones, sería asimismo posible que entrara en primer lugar en el huésped por la vía respiratoria, llegara al tejido pulmonar con posterioridad, se mezclase con las secreciones respiratorias, fuera entonces expectorado, luego deglutido este exputo (cargado de larva) y por último pasase al tracto gastro-intestinal. Existen ciertos parásitos que realizan este enrevesado trayecto, como por ejemplo los esquistosomas, tan prevalentes a nivel mundial.

Asumiendo su presumible ocupación en el estómago, Alien abandona el cuerpo del hospedador casi siempre por la parte anterior del tronco (salvo en dos excepciones, en Alien: Covenant (2017), donde sale por la espalda, a la altura de las vértebras torácicas, y por la boca, respectivamente). La salida anterior se produce por la región que va desde la parte inferior del tórax a la parte superior del abdomen, entre el esternón y el plano transpilórico, a la altura del epigastrio. En casi todos los casos, cuando la criatura emerge, suele haber destrucción de elementos óseos de la caja torácica (Foto 5): en Prometheus (2012) se ven fracturas de costillas (presumiblemente entre la VI y la $X$ ) y esternón (tal vez con rotura del manubrio). En este amplio entorno, también se dañarían otras estructuras como diferentes cartílagos costales, la apófisis xifoides, la musculatura abdominal y órganos blandos como el hígado o los pulmones. Además, en Alien: Resurección (1997), la protagonista Ripley presenta una cicatriz horizontal justo en la caja torácica (a la altura del diafragma), fruto de una intervención quirúrgica para extraer a la criatura. En esta obra, incluso, la teniente interpretada por Sigourney Weaver asegura «tienes un monstruo dentro y te estallará la caja torácica», al dialogar con un tripulante infectado.

La especie Alien puede utilizar otros hospedadores diferentes del ser humano: en la tercera entrega de la saga aparecen perros, y en Prometheus (2012) se muestra a unos extraterrestres humanoides llamados «Ingenieros». Curiosamente, tanto la morfología del individuo juvenil como del adulto difiere según quien sea el huesped. La única justificación biológica del tal hecho (aunque desde luego no se conoce ningún caso animal en la naturaleza), sería algún tipo de recombinación génica con el hospedador (al modo del intercambio genético que los virus realizan con el material génico de la célula infectada) o, más plausiblemente, la posibilidad de que el entorno humoral del individuo parasitado haya podido afectar el desarrollo embrionario -y, finalmente, fenotípico- de la criatura. De hecho, algo similar a esto último sucede durante la embriogénesis del aparato reproductor humano: la presencia o ausencia de determinadas 


\section{DESCRIPCIÓN Y ANÁLISIS DEL CONTENIDO BIOMÉDICO EN LAS PELÍCULAS DE LA SAGA ALIEN}

JOSÉ MIGUEL BISCAIA FERNÁNDEZ; ROSA BELÉN MOHEDANO DEL POZO

hormonas (como la testosterona, la dihidrotestosterona o la hormona antimullëriana) es clave en la diferenciación genital masculina y femenina.

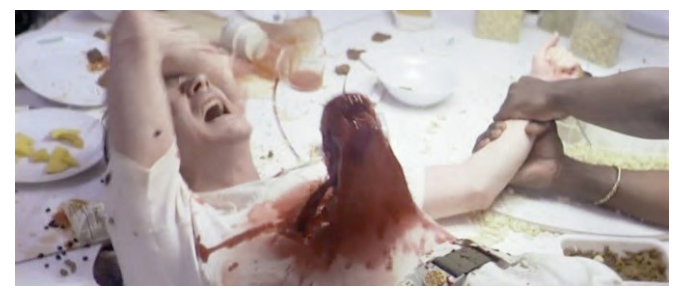

Foto 5. Alien emergiendo del cuerpo del huésped humano.

Tras todo lo expuesto, la critatura Alien podría considerarse, pues, un endoparasitoide solitario. Esta categorización es más ajustada que la de parásito, puesto que su ciclo de vida supone necesariamente la muerte del hospedador. Como ya se ha dicho, la fase infectiva es en apariencia larvaria, también facultativa, dado que supone un muy breve periodo de todo su ciclo vital, la mayoría del cual se produce en forma libre e independiente del huésped (como sucede con algunas especies de moscas y avispas parasitoides). Además, su ciclo de vida podría recordar igualmente al de los parásitos monoxenos, es decir, aquellos que utilizan a un único hospedador ${ }^{11}$.

En Prometheus (2012) aparecen otras formas parasitoides / parasitarias. Por un lado, se muestra una especie de criaturas filiformes de unos pocos milímetros que infectan por vía oral. También, una especie de lamprea de aproximadamente un metro que accede por la misma vía. En este último caso, el huesped humano ve modificada su conducta, lo cual conduce a cierta analogía con el virus de la rabia (familia Rhaddoviridae), el cual provoca encefalitis e importantes cambios neurológicos y conductuales; o analogía también con algunas larvas de moscas y avispas (por ejemplo, de las familias Ichneumonidae y Braconidae), que modifican radicalmente el comportamiento de sus hospedadores invertebrados (tal es el caso del coleóptero Coleomegilla maculata) ${ }^{12}$. Con respecto a las larvas filiformes citadas más arriba, durante el proceso infeccioso deben tener un fácil acceso a otras partes corporales, ya que en una escena uno de los personajes las descubre sobre la esclera de su ojo, y en otra secuencia dichas larvas infectan a una mujer tras mantener una relación sexual con un varón (en cierta alusión a las Enfermedades de Transmisión Sexual, ETS).

Alien: Covenant (2017), la última obra de la saga, también muestra otras formas parasitarias que guardan alguna similitud, en este caso, con hongos infecciosos: se distinguen una especie de esporas saliendo de algo similar a una seta, que en apariencia avanzan de forma dirigida -tal vez quimiotácticamente- hacia orificios de entrada corporal, como la nariz o el conducto auditivo de la víctima. Poco tiempo después, eclosiona una variante de la criatura Alien de morfología ligeramente diferente a lo visto en otras obras (lo más curioso es que emerge rodeada por una especie de envoltura que recuerda al amnios de los mamíferos placentarios).

Otro apunte microbiológico interesante lo encontramos en el hecho de que en una escena de Prometheus (2012), los exploradores humanos descubren el cuerpo incorrupto -durante milenios-de varios «Ingenieros». Su estado de conservación podría indicar que en el planeta en el que se hallan no hay presencia de microorganismos (u otras especies cadavéricas propias de los «escuadrones de la muerte») responsables del proceso de putrefacción.

La saga fílmica analizada ofrece también dos interesantes apuntes sobre un proceso clave en lo que a las enfermedades infecciosas y la salud pública se refiere: la cuarentena. En Alien: Covenant (2017), no se respeta dicho periodo de vigilancia ante la evidente infección de uno de los tripulantes de la nave espacial. Por el contrario, en Prometheus (2012) se pone un excesivo celo al respecto de dicho protocolo: la capitana de la nave decide quemar vivo a uno de sus subalternos al descubrir que se encuentra contagiado.

Terminamos poniendo el acento en un hecho de interés microbiológico doblemente comentado, en las dos últimas obras de la saga: la guerra biológica. En Prometheus (2012), queda de manifiesto que la criatura Alien no es más que un proyecto incipiente de arma biológica destinada a destruir a la humanidad. En Alien: Covenant (2012), el androide interpretado por el actor Michael Fassbender pone en práctica la amenaza destruyendo a la población extraterrestre del planeta donde se desarrolla la trama. El uso de armas biológicas no es desde luego algo nuevo: en el 400 a.C. se impregnaban flechas con tejidos descompuestos, y en el año 1346 de nuestra era, los tártaros catapultaban cuerpos enfermos de peste. En la Guerra chino-japonesa de 1930, se usaron pulgas para propagar enfermedades y, más recientemente, se han usado agentes infecciosos como Bacillus anthracis (productor del carbunco), Vibrio cholerae (productor del cólera), la toxina botulínica procedente de Clostridium botulinum o el virus de la viruela en varios ataques terroristas. Ante el avance en el desarrollo de 


\section{DESCRIPCIÓN Y ANÁLISIS DEL CONTENIDO BIOMÉDICO EN LAS PELÍCULAS DE LA SAGA ALIEN JOSÉ MIGUEL BISCAIA FERNÁNDEZ; ROSA BELÉN MOHEDANO DEL POZO}

armas biológicas, se estableció un control de las mismas en 1969 (con la creación del Programa de Destrucción de Armas Biológicas) y en 1972 se creó la Convención Internacional de Armas $^{11}$.

\section{Conclusiones}

1. Las películas de la saga Alien contienen una muy rica y variada temática científico-tecnológica, particularmente en el área de la biomedicina.

2. Desde una perpectiva biosanitaria, las películas de la saga Alien ofrecen un interesante repertorio de temáticas médicas que perfectamente podrían ser utilizadas en el estudio de la Anatomía, la Fisiología, la Microbiología o la Parasitología, entre otras disciplinas. Proponemos, pues, para futuras investigaciones en el ámbito de la innovación docente, la estructuración formal de una actividad académica que pueda ser utilizada en asignaturas de grados biosanitarios como Medicina, Enfermería, Fisioterapia, Farmacia u Odontología.

\section{Referencias}

1. Ziman J. Prometheus Bound. Science in a Dynamic Steady State. Cambridge: Cambridge University Press; 1994.

2. Fitzgerald BW. The physiology of impenetrable skin: Colossus of the X-Men. Ad Physiol Educ. 2018;42(4):529-40.

3. Brown SP, Smith JW, McAllister M, Joel L. Superhero physiology: the case for Captain America. Ad Physiol Educ. 2017;41(1):16-24.
4. Schneider DS. What Can Vampires Teach Us about Immunology? Trends Inmunol. 2016; 37(4):253-6.

5. Toye F, Jenkins S, Seers K, Barker K. Exploring the value of qualitative research films in clinical education. BMC Med Educ. 2015;15:214.

6. Shankar PR, Rose C, Balasubramanium R, Nandy A, Friedmann A. Using Movies to Strengthen Learning of the Humanistic Aspects of Medicine. J Clin Diagn Res. 2016;10(1):JC05-JC7.

7. Ogston-Tuck S, Baume K, Clarke C, Heng S. Understanding the patient experience through the power of film: A mixed method qualitative research study. Nurse Educ Today. 2016; 46:69-74.

8. Boletín Oficial del Estado. Real Decreto 415/2015, de 29 de mayo, por el que se modifica el Real Decreto 1312/2007, de 5 de octubre, por el que se establece la acreditación nacional para el acceso a los cuerpos docentes universitarios. BOE núm. 144. de 17 de junio de 2015.

9. Murray P, Rosenthal K, Pfaller M. Microbiología Médica. 8a ed. Barcelona: Elsevier España; 2017.

10. Velasquez JJ. Efecto anestésico local del extracto glandular salival del hematófago Rhodnius prolixus [tesis doctoral]. Bogotá: Universidad Nacional de Colombia; 2017.

11. Romero R. Microbiología y parasitología humana: bases etiológicas de las enfermedades infecciosas y parasitarias. 3a ed. México: Médica Panamericana; 2007.

12. Dheilly NM, Maure F, Ravallec M, Galinier R, Doyon J, Duval $D$, et al. Who is the puppet master? Replication of a parasitic wasp-associated virus correlates with host behaviour manipulation. Proc Biol Sci. 2015;282(1803):20142773.

\begin{tabular}{|l|l|}
\hline & $\begin{array}{l}\text { Rosa Belén Mohedano del Pozo es Licenciada y Doctora en Medicina, Especialista en Micro- } \\
\text { biología Clínica, Diplomada en Fisioterapia y Máster en Trastornos del Comportamiento } \\
\text { Alimentario. Ha trabajado en varios hospitales públicos como infectóloga. Actualmente } \\
\text { trabaja como profesora en la Universidad Europea de Madrid, impartiendo clases de } \\
\text { Microbiología, Epidemiología y Bioestadística en el grado de Medicina. Investiga en el } \\
\text { área de la Epidemiología. }\end{array}$ \\
\hline $\begin{array}{l}\text { José Miguel Biscaia Fernández es Licenciado y Doctor en Biología y Máster en Biotecno- } \\
\text { logía. Se ha dedicado a la investigación básica en varias universidades nacionales e inter- } \\
\text { nacionales. Actualmente trabaja como profesor en la Universidad Europea de Madrid, } \\
\text { impartiendo clases de Anatomía y Fisiología Humana en el grado de Medicina. Investiga } \\
\text { en el área de las Neurociencias. }\end{array}$
\end{tabular}

